\title{
Peripheral vascular interventions: An illustrated manual
}

Authors: Juergen Schroeder

Publisher: Thieme Medical Publishers

Edition: $1^{\text {st }}$

Pages: 220 pages, 570 illustrations

This manual has been written and illustrated by a practitioner with many years of hands-on experience.

The initial chapters of the book are devoted to "materials" and "methods" in peripheral vascular interventions. Fundamental concepts about catheters, guidewires, sheaths, balloon catheters and stents are discussed. Technique of peripheral vascular access and catheterization techniques are described in detail with plenty of schematic illustrations. The important principles to be followed while performing angiography are rationalized along with recommendations to optimize the DSA equipment available to the user. The section ends with a compact discussion on angioplasty, stenting, thrombolysis, embolization and intravascular foreign body retrieval.

The second half discusses interventions of stenosis in renal arteries, aortoiliac segment and lower extremity arterial segments. Indications, patient preparation, intervention technique, results are discussed with technical recommendations from literature, risks and complications as well as tips from author's personal experience. The chapter on upper extremity interventions discusses treatment of subclavian artery stenosis, dialysis shunt stenosis and thrombosis, central venous stenosis and superior vena cava syndrome.

As the title suggests, the focus of the book is on peripheral vascular interventions. Other endovascular interventions are briefly described in a separate chapter with deliberate omission of details.

The book is addressed to the needs of beginners. Practical aspects of performing peripheral vascular procedures are discussed in detail, conventional precepts and recommendations in literature are analyzed and reasoned. A rich feature of the book is the abundant use of schematic drawings to explain each step of the procedure.

As the title mentions, it is an illustrated manual and not intended to replace the customary textbooks. The book will be very useful for residents, fellows and the beginning interventional radiologist.

Ravi Varma

Department of Radiology, Topiwala National Medical College and BYL Nair Charitable Hospital, Mumbai Central, Mumbai - 400 008, Maharashtra, India. E-mail: ravi_varma_2004@yahoo.co.in

\begin{tabular}{|l|l|}
\hline \multicolumn{2}{|c|}{ Access this article online } \\
\hline Quick Response Code: & \\
\hline & \\
\hline
\end{tabular}

